\title{
Autologous fibrin sealant application in cardiac surgery - a single-centre observational study
}

\author{
Radosław Jarząbek ${ }^{1}$, Krzysztof Greberski², Paweł Bugajski \\ ${ }^{1}$ Department of Cardiac Surgery, J. Struś Municipal Hospital, Poznan, Poland \\ ${ }^{2}$ Faculty of Health Sciences, University of Medical Sciences, Poznan, Poland
}

Kardiochirurgia i Torakochirurgia Polska 2021; 18 (2): 75-79

\begin{abstract}
Introduction: To minimize the risk of blood loss and post-transfusion complications in patients undergoing cardiovascular surgery, different strategies are used.

Aim: To analyse the efficacy of the intraoperative use of autologous fibrin glue to seal suture lines of cardiac and vascular structures.

Material and methods: The early results of 62 patients who underwent complex cardiac operations in extracorporeal circulation were analysed. In a half of them Vivostat autologous fibrin sealant in addition to the routine haemostatic agents was applied (study group), whereas in the second group (matched-pair control group) only standard haemostatics were used. Among many other factors, special attention was paid to postoperative drainage and blood products used.

Results: The mean age of the patients and prevalence of comorbidities did not differ between groups. Generally, in the study group fewer haemostatic agents were used. For example, Preveleak tissue glue was applied in $3.2 \%$ of studied cases compared to one third of control patients $(p=0.008)$. The thoracic drainage on either day 0 or day 1 was also similar. The number of patients who received blood products did not differ between groups. More importantly, there were no significant differences in in-hospital mortality and prevalence of other postoperative complications.

Conclusions: In this study it was found that application of autologous fibrin glue was safe and might limit use of standard haemostatic agents. Taking into account the lack of potential threats related to the transmission of infections and immune responses, it may be an interesting alternative to the previously used local haemostatics.
\end{abstract}

Key words: autologous fibrin sealant, Vivostat, cardiac surgery.

\section{Introduction}

Despite the continuous technological progress in medicine, blood products remain difficult to replace, and they are often indispensable. The vast majority of patients undergoing cardiac surgical operations need transfusions of blood products, particularly those qualified for complex procedures [1]. Many factors such as relatively long operation time, the need for extracorporeal circulation, haemodilution, hypothermia, and the risk of perioperative bleeding contribute to blood loss [2]. However, transfusions entail potential complications such as adverse excessive immune reactions, viral infection transmissions, and may constitute a significant part of the treatment costs [3-8].

To minimize the risk of blood loss and post-transfusion complications in patients undergoing cardiovascular surgical procedures, different strategies are used. Several methods for sealing surgical suture lines, such as patches, adhesives or haemostats, have been developed [9]. Some include pro-clotting factors derived from donor plasma pools or fully synthetic products that do not interfere with the blood coagulation cascade [9]. In this aforementioned context, an ideal agent would be a fibrin sealant obtained intraoperatively from the patient's blood. Having a potentially effective surgical sealant it is possible to avoid exposing the patient to synthetic products and those from foreign donors. Moreover, the first reports of its clinical application in high-risk patients as well as our initial experience together with economic cost analysis encouraged us to use it more often in selected surgical cases [10-18].

\footnotetext{
Aim

In this study, the safety and efficacy as well as early clinical outcomes of the intraoperative use of autologous fibrin glue to seal suture lines of cardiac and vascular structures have been evaluated.
} 
Table I. Demographics

\begin{tabular}{|c|c|c|c|c|c|}
\hline \multirow{2}{*}{$\begin{array}{l}\text { Parameter } \\
N\end{array}$} & \multicolumn{2}{|c|}{$\begin{array}{c}\text { Autologous } \\
\text { sealant group }\end{array}$} & \multicolumn{2}{|c|}{ Control group } & \multirow[t]{2}{*}{$P$-value } \\
\hline & \multicolumn{2}{|r|}{31} & \multicolumn{2}{|r|}{31} & \\
\hline \multicolumn{6}{|l|}{ Sex: } \\
\hline Male & 22 & $70.9 \%$ & 23 & $74.2 \%$ & 1.0 \\
\hline Female & 9 & $29.0 \%$ & 8 & $25.8 \%$ & 1.0 \\
\hline Age [years] & 60.4 & \pm 10.3 & 63.1 & \pm 8.3 & 0.3 \\
\hline BMI $\left[\mathrm{kg} / \mathrm{m}^{2}\right]$ & 28.9 & \pm 4.7 & 28.5 & \pm 4.4 & 0.7 \\
\hline Diabetes & 6 & $19.4 \%$ & 9 & $29.0 \%$ & 0.6 \\
\hline Hyperlipidaemia & 30 & $96.8 \%$ & 31 & $100.0 \%$ & 1.0 \\
\hline \multicolumn{6}{|l|}{ Smoking history: } \\
\hline Former smoker & 16 & $51.6 \%$ & 13 & $41.9 \%$ & 0.6 \\
\hline Current smoker & 9 & $29.0 \%$ & 13 & $41.9 \%$ & 0.4 \\
\hline Renal impairment & 12 & $38.7 \%$ & 11 & $35.5 \%$ & 1.0 \\
\hline NYHA class III and IV & 4 & $12.9 \%$ & 3 & $9.7 \%$ & 1.0 \\
\hline $\begin{array}{l}\text { Previous myocardial } \\
\text { infarction }\end{array}$ & 4 & $12.9 \%$ & 3 & $9.7 \%$ & 1.0 \\
\hline Previous PCl & 1 & $3.2 \%$ & 1 & $3.2 \%$ & 1.0 \\
\hline Arterial hypertension & 28 & $90.3 \%$ & 30 & $96.8 \%$ & 0.6 \\
\hline Asthma & 0 & $0.0 \%$ & 0 & $0.0 \%$ & 1.0 \\
\hline COPD & 2 & $6.5 \%$ & 5 & $16.1 \%$ & 0.4 \\
\hline $\begin{array}{l}\text { Pulmonary } \\
\text { hypertension }\end{array}$ & 18 & $58.1 \%$ & 18 & $58.1 \%$ & 1.0 \\
\hline $\begin{array}{l}\text { Extracardiac } \\
\text { arteriopathy }\end{array}$ & 24 & $77.4 \%$ & 28 & $90.3 \%$ & 0.3 \\
\hline Poor mobility & 4 & $12.9 \%$ & 7 & $22.6 \%$ & 0.5 \\
\hline LV ejection fraction (\%) & 51.1 & \pm 11.0 & 49.3 & \pm 13.0 & 0.6 \\
\hline Log EuroSCORE II & 4.1 & \pm 3.6 & 4.5 & \pm 3.6 & 0.7 \\
\hline
\end{tabular}

BMI - body mass index, NYHA - New York Heart Association, COPD - chronic obstructive pulmonary disease, LV - left ventricle, $\mathrm{PCl}$ - percutaneous coronary intervention.

Table II. Intraoperative data

\begin{tabular}{lccccc} 
Parameter & $\begin{array}{c}\text { Autologous } \\
\text { Sealant group }\end{array}$ & \multicolumn{2}{c}{ Control group } & P-value \\
$N$ & \multicolumn{2}{c}{31} & \multicolumn{2}{c}{31} \\
\hline $\begin{array}{l}\text { Aortic aneurysm } \\
\text { repair }\end{array}$ & 16 & $51.6 \%$ & 16 & $51.6 \%$ & N/A \\
\hline AVR & 3 & $9.7 \%$ & 3 & $9.7 \%$ & N/A \\
\hline miniAVR & 6 & $19.4 \%$ & 6 & $19.4 \%$ & N/A \\
\hline AVR + CABG & 6 & $19.4 \%$ & 6 & $19.4 \%$ & N/A \\
\hline $\begin{array}{l}\text { Cross clamping } \\
\text { time }\end{array}$ & 91.4 & \pm 30.8 & 72.7 & \pm 21.8 & 0.011 \\
\hline ECC time & 128.3 & \pm 39.2 & 111.7 & \pm 35.2 & 0.1 \\
\hline TachoSil & 4 & $12.9 \%$ & 9 & $29.0 \%$ & 0.2 \\
\hline Preveleak & 1 & $3.2 \%$ & 10 & $32.7 \%$ & 0.008 \\
\hline 4dryfield & 2 & $6.5 \%$ & 5 & $16.1 \%$ & 0.4 \\
\hline
\end{tabular}

AVR - aortic valve replacement, CABG - coronary artery by-pass grafting, ECC extracorporeal circulation, N/A - not applicable.

\section{Material and methods Patients}

A total of 62 patients who underwent elective but complex cardiac surgical procedures in the extracorporeal circulation in the years 2018 to 2019 were enrolled in the study. In 31 of them, autologous fibrin sealant in addition to the standard haemostatic agents was applied (the study group). The second group comprised subjects of the same gender and at a similar age and undergoing cardiac surgical procedures of comparable complexity, in whom only standard haemostasis enhancing methods were used (matched-pair control group). Demographic, selected preoperative clinical data (including the most basic echocardiographic findings and surgical risk according to the EuroSCORE scale) of enrolled patients are presented in Table I.

\section{Surgery and fibrin glue application}

All procedures were performed with extracorporeal circulation (ECC) involving transverse aorta clamping via a median sternotomy or upper hemisternotomy. The type of surgery performed is outlined in Table II. Bretschneider cold crystalloid cardioplegia was employed as a protective myocardial method. The decision to use the tested Vivostat fibrin glue (Vivostat A/S, Alleroed, Denmark) was left to the discretion of the surgeon, who always had at his disposal other routinely used haemostatic agents.

Vivostat fibrin glue was prepared in the initial stage of the procedure from approximately $120 \mathrm{ml}$ of the patient's blood taken from the radial artery before introduction of ECC. The kit for the production of fibrin glue is a fully automated system consisting of two mobile modules (Figure 1). The first unit is for preparation of the fibrin sealant from autologous blood whereas the second one is for delivery of the agent in the form of a spray through a disposable applicator tip. During one preparation cycle of a single-use set, approximately $5 \mathrm{ml}$ of sealant is derived after $20 \mathrm{~min}$, which can be used many times during the operation. It should be noted that in both groups, other local haemostatic agents were also used if necessary, as shown in Table II.

\section{Postoperative course assessment}

Regarding patients' postoperative course, special attention was paid to the volume of drainage on postoperative days 0 and 1 as well as the number of patients who received blood products (Table III). Early (defined as up to 30 days after surgery) mortality and prevalence of postoperative complications were evaluated (Table IV).

Eventually, we calculated costs of treatment when autologous fibrin glue was used and compared them to the other available haemostatic agents.

\section{Statistical analysis}

The R environment was used for statistical calculations [19]. Mean values of continuous variables were compared using Student's $t$ test (if normally distributed) or their medians by means of the Mann-Whitney $U$ test (the other 


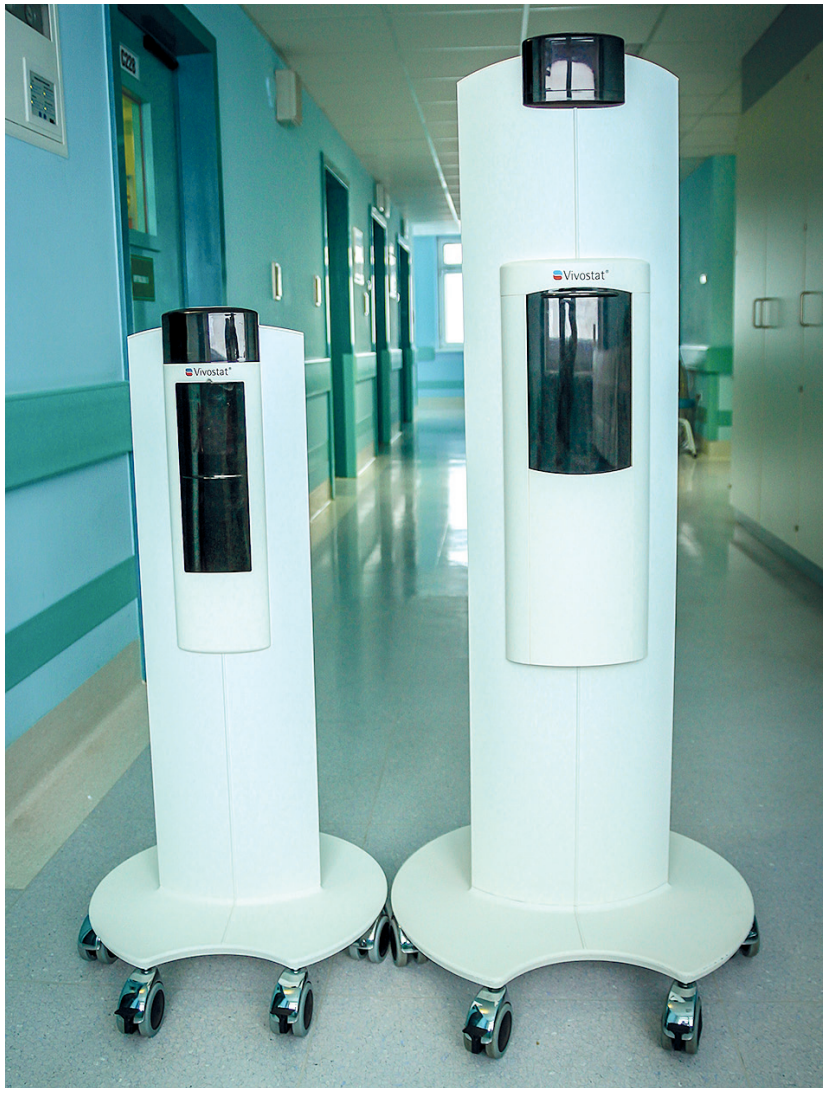

Figure 1. The two indispensable modules of the set for producing the Vivostat fibrin sealant

variables). Qualitative data were compared using the $\chi^{2}$ test or Fisher's exact test. $P<0.05$ was considered statistically significant.

\section{Results}

Owing to the matching procedure, patients in the study and control groups did not differ between one another with respect to age, gender, comorbidities, echocardiographic findings or estimated risk of surgery.

The most often performed surgical procedures in both groups were operations for ascending aortic aneurysms ( $n=16$; isolated supracoronary implantation of aortic prostheses and the Bentall-De Bono and David operations) followed by aortic valve replacement combined with aortocoronary bypass grafting $(n=6)$. As the types of surgery were one of the key factors in the selection of the control group, they did not differ between groups. Of note, although the mean time of ECC was comparable, the aortic clamp time was found to be significantly longer in the study group. With respect to the haemostatic agents, Vivostat application enabled 10-fold reduction in use of Preveleak glue (Baxter International Inc., Deerfield, IL, USA) from 32.3\% to only $3.2 \%(p=0.008)$. The rate of other agents usage such as TachoSil (Takeda Austria GmbH, Linz, Austria) and 4DryField (PlantTech Medical GmbH, Luneburg, Germany) was similar in both subsets of patients. Details regarding operations are listed in Table II.
Table III. Postoperative data

\begin{tabular}{|c|c|c|c|c|c|}
\hline \multirow{2}{*}{$\begin{array}{l}\text { Parameter } \\
N\end{array}$} & \multicolumn{2}{|c|}{$\begin{array}{c}\text { Autologous } \\
\text { sealant group }\end{array}$} & \multicolumn{2}{|c|}{ Control group } & \multirow[t]{2}{*}{$P$-value } \\
\hline & & 31 & & 31 & \\
\hline $\begin{array}{l}\text { Drainage on } \\
\text { day } 0[\mathrm{ml}]\end{array}$ & 350 & $110-2050$ & 400 & $50-1700$ & 0.9 \\
\hline $\begin{array}{l}\text { Drainage on } \\
\text { day } 1[\mathrm{ml}]\end{array}$ & 290 & $110-850$ & 300 & $90-820$ & 0.7 \\
\hline RBC & 28 & $90.3 \%$ & 30 & $96.8 \%$ & 0.6 \\
\hline FFP & 23 & $74.2 \%$ & 20 & $64.5 \%$ & 0.6 \\
\hline PC & 11 & $35.5 \%$ & 4 & $12.9 \%$ & 0.1 \\
\hline Cryo & 4 & $12.9 \%$ & 4 & $12.9 \%$ & 1 \\
\hline PCC & 16 & $51.6 \%$ & 12 & $38.7 \%$ & 0.4 \\
\hline Fibrinogen & 3 & $9.7 \%$ & 1 & $3.2 \%$ & 0.6 \\
\hline $\begin{array}{l}\text { Length of stay } \\
\text { after surgery } \\
\text { [days] }\end{array}$ & 9.7 & \pm 3.9 & 8.8 & \pm 0.5 & 0.4 \\
\hline
\end{tabular}

RBC - red blood cell concentrate, FFP - fresh frozen plasma, PC - platelet concentrate, Cryo - cryoprecipitate; $\mathrm{PCC}$ - prothrombin complex concentrate.

Table IV. Incidence of complications

\begin{tabular}{|c|c|c|c|c|c|}
\hline \multirow{2}{*}{$\begin{array}{l}\text { Parameter } \\
\text { N }\end{array}$} & \multicolumn{2}{|c|}{$\begin{array}{l}\text { Autologous } \\
\text { sealant group }\end{array}$} & \multicolumn{2}{|c|}{ Control group } & \multirow[t]{2}{*}{$P$-value } \\
\hline & & 31 & & 31 & \\
\hline $\begin{array}{l}\text { Reoperation due to } \\
\text { bleeding }\end{array}$ & 6 & $19.4 \%$ & 5 & $16.1 \%$ & 1 \\
\hline Stroke & 0 & $0.0 \%$ & 0 & $0.0 \%$ & 1 \\
\hline Dialysis & 2 & $6.5 \%$ & 3 & $9.7 \%$ & 1 \\
\hline Respiratory failure & 1 & $3.2 \%$ & 1 & $3.2 \%$ & 1 \\
\hline $\begin{array}{l}\text { Clostridium difficile } \\
\text { diarrhoea }\end{array}$ & 0 & $0.0 \%$ & 1 & $3.2 \%$ & 1 \\
\hline Mediastinal infection & 0 & $0.0 \%$ & 1 & $3.2 \%$ & 1 \\
\hline Pacemaker implantation & 1 & $3.2 \%$ & 0 & $0.0 \%$ & 1 \\
\hline 30-day mortality & 1 & $3.2 \%$ & 1 & $3.2 \%$ & 1 \\
\hline
\end{tabular}

AVR - aortic valve replacement, CABG - coronary artery by-pass grafting, ECC extracorporeal circulation, N/A - not applicable.

In-hospital mortality in both groups was identical (3.2\%) and was not associated with bleeding complications (Table IV). Excessive postoperative haemorrhage requiring chest exploration was comparable between groups. In both groups, drainage did not differ significantly between the groups on either day 0 or day 1 (Table III). The transfusions of blood products such as red blood cell concentrate (RBC), fresh frozen plasma (FFP), platelet concentrate (PC), cryoprecipitate (Cryo) or concentrates of prothrombin factors and fibrinogen were comparable between the groups.

There were no statistically significant differences in the incidence of serious adverse events such as stroke, acute respiratory failure, renal failure requiring renal replacement therapy, mediastinal infection, Clostridium difficile diarrhoea, and cardiac blocks treated with permanent pacemaker implantations (Table IV). The groups did not differ 
significantly in terms of the length of stay after surgery ( 9.7 \pm 3.9 vs. $8.8 \pm 0.5$ days).

Our calculations show that compared with that of the tissue adhesives typically used in our hospital, the cost of using a single dose of Vivostat (the consumption of a disposable preparation kit and applicator) is approximately $20 \%$ lower for an equivalent volume of agent.

\section{Discussion}

The blood loss-reducing strategy in cardiac surgery is primarily dictated by the patient's safety in terms of limiting the side effects related to transfusions. We cannot also ignore the economic aspects; collecting blood products from donors is expensive and not always able to fulfil the patients' needs, as it has been seen in the era of the SARS-CoV-2 epidemic [20]. Therefore, the use of various strategies to reduce intra- and postoperative blood loss is fully justified. One such method is the use of local agents applied to vascular anastomoses and other sources of bleeding in the operating field [9]. However, most of them are produced from human or animal components and are considered as foreign substances to the patient, potentially inducing an immune response $[5,6]$. Products of human origin containing fibrin or thrombin from numerous donors may be associated with the transmission of viruses and prions [7, 8, 21]. The use of animal products (bovine thrombin, equine collagen) reduces the risk of transmission of infection but may cause the production of antibodies, which in rare cases leads to anaphylactic reactions (e.g., coagulopathy) $[7,8,22]$. Contrary to the aforementioned agents, the autologous fibrin sealant Vivostat is produced on-site in the operating room from the own patient's blood, and thus is free from the previously described potential adverse reactions related to use of foreign products, either human or animal. In 2017 we applied the autologous fibrin sealant Vivostat for the first time in a complex surgical procedure of ascending aortic prosthesis implantation and aortic valve replacement [10].

Vivostat has been used in clinical practice for over 20 years. The beneficial effects of this sealant in thoracic surgery, neurosurgery, gastroenterological surgery, laryngological and other surgical disciplines have been well documented [12, 13, 15-18, 23]. Although the outlook is optimistic, still limited data are available on Vivostat application in cardiac surgery. The above reports and our own experience with the first use of the Vivostat sealant in a cardiac surgery department in Poland encouraged us to introduce this agent to our daily clinical practice and then share our experience with its usage.

Although autologous fibrin glue did not translate into fewer transfusions in our group, at least one positive message may be drawn from our study. The most important finding is the fact that Vivostat enabled at least partial reduction in the use of other foreign haemostatic agents. Having in mind possible adverse events related to application of substances of foreign origin, it must be treated as a positive result. Moreover, some practical issues, too diffi- cult to estimate intraoperatively and analysed statistically, must be pointed out. The relatively flexible layer placed on the tissues effectively adheres to the movable walls of the vessel and is easily penetrated by a surgical suture. Some tissue glues lack this unique property. Additionally, a single dose of Vivostat can be used until the cartridge is empty for many hours without changing the applicator, which differs from many other haemostatic agents.

Although the subsets of patients were matched in terms of surgical complexity, among others, the mean aortic cross clamping time was longer, which may indicate more challenging intracardiac anatomy (and hence procedures) found during the operation. The longer ischemic period of ECC could impact negatively on intraoperative blood loss or damage. The previous reports with respect to volume of the postoperative drainage and use of blood products are unequivocal. Kjaergard and Trumball reported lower volumes of drainage in 12 out of 24 patients undergoing coronary artery bypass grafting (CABG), but the difference in the whole group was not statistically significant [11]. However, fewer individuals had transfusions. In a more recent study by Wiedemann et al., who analysed 122 isolated CABG patients, postoperative drainage was not compared but they did not find any differences regarding volume and number of subjects requiring transfusions [14]. No significant difference in the volume of postoperative drainage was noted by Kilic et al. in a prospective randomized study from 2017 comparing the effectiveness of Vivostat with the homologous Tisseel fibrin sealant in patients undergoing pulmonary resection [17]. Of note, in none of the three abovementioned studies did patients undergo combined cardiac surgical procedures as in our group. Therefore, our findings should be compared to the previous reports with particular caution.

We are aware of some obvious study limitations. This research is a retrospective single-centre study involving a relatively small group of patients. Moreover, they were not operated on by the same surgeon. However, all subjects were treated by persons with many years of experience in aortic and valvular surgery. As mentioned above, the type of surgical sealant used was left to the individual surgeon's independent decision. It may cause bias in comparing the rate and types of agents to apply. Regardless of the above, our study warranty further research in clinical applicability of methods supporting cardiac surgeons to achieve optimal surgical haemostasis in high risk individuals.

\section{Conclusions}

This study showed that application of autologous fibrin glue was safe and might limit the use of standard haemostatic agents. Taking into account the lack of potential threats related to the transmission of infections and immune responses, it may be an interesting alternative to the previously used local haemostatics.

\section{Disclosure}

The authors report no conflict of interest. 


\section{References}

1. Uehlinger J, Aledort LM. Blood-product usage in cardiac surgery. J Cardiothorac Anesth 1989; 3: 776-84.

2. Parr KG, Patel MA, Dekker R, Levin R, Glynn R, Avorn J, Morse DS. Multivariate predictors of blood product use in cardiac surgery. J Cardiothorac Vasc Anesth 2003; 17: 176-81.

3. Chavez AM, Cosgrove DM 3rd. Blood conservation. Semin Thorac Cardiovasc Surg 1990; 2: 358-63.

4. Ranucci M, Baryshnikova E, Castelvecchio S, Pelissero G; Surgical and Clinical Outcome Research (SCORE) Group. Major bleeding, transfusions, and anemia: the deadly triad of cardiac surgery. Ann Thorac Surg 2013; 96: 478-85.

5. Lawson JH. The clinical use and immunologic impact of thrombin in surgery. Semin Thromb Hemost 2006; 32: 98-110.

6. Rothwell SW, Sawyer E, Dorsey J, Flournoy WS, Settle T, Simpson D, Cadd G, Janmey P, White C, Szabo KA. Wound healing and the immune response in swine treated with a hemostatic bandage composed of salmon thrombin and fibrinogen. J Mater Sci Mater Med 2009; 20: 2155-66.

7. Kleinerüschkamp A, Meybohm P, Straub N, Zacharowski K, Choorapoikayil S. A model-based cost-effectiveness analysis of patient blood management. Blood Transfus 2019; 17: 16-26.

8. Spotnitz WD. Fibrin sealant: the only approved hemostat, sealant, and adhesive-a laboratory and clinical perspective. ISRN Surg 2014; 2014: 203943.

9. Spotnitz WD. Fibrin sealant: past, present, and future: a brief review. World J Surg 2010; 34: 632-4.

10. Jarząbek R, Bugajski P, Greberski K, Kalawski R. The use of an autologous fibrin sealant during a complex cardiac surgical procedure. Kardiochir Torakochir Pol 2018; 15: 62-4.

11. Kjaergard HK, Trumbull HR. Vivostat system autologous fibrin sealant: preliminary study in elective coronary bypass grafting. Ann Thorac Surg 1998; 66: 482-6.

12. Belboul A, Dernevik L, Aljassim O, Skrbic B, Rådberg G, Roberts D. The effect of autologous fibrin sealant (Vivostat) on morbidity after pulmonary lobectomy: a prospective randomised, blinded study. Eur J Cardiothorac Surg 2004; 26: 1187-91
13. Schips L, Dalpiaz O, Cestari A, Lipsky K, Gidaro S, Zigeuner R, Petritsch P. Autologous fibrin glue using the Vivostat system for hemostasis in laparoscopic partial nephrectomy. Eur Urol 2006; 50: 801-5.

14. Wiedemann D, Vill D, Bonaros N, Laufer G, Schachner T, Kocher A. Topical use of autologous fibrin glue in high-risk CABG patients. Eur Surg 2011; 43: 309-14.

15. Belcher E, Dusmet M, Jordan S, Ladas G, Lim E, Goldstraw P. A prospective, randomized trial comparing BioGlue and Vivostat for the control of alveolar air leak. J Thorac Cardiovasc Surg 2010; 140: 32-8.

16. Hanks JB, Kjaergard HK, Hollingsbee DA. A comparison of the haemostatic effect of Vivostat patient-derived fibrin sealant with oxidised cellulose (Surgicel) in multiple surgical procedures. Eur Surg Res 2003; 35: 439-44.

17. Kılıç B, Erşen E, Demirkaya A, Kara HV, Alizade N, İşcan M, Kaynak K, Turna A. A prospective randomized trial comparing homologous and autologous $\mathrm{fi}$ brin sealants for the control of alveolar air leak. J Thorac Dis 2017; 9: 2915-22.

18. Luu AM, Braumann C, Uhl W, Janot-Matuschek M, Herzog T. Does autologous fibrin sealant $\left(\right.$ vivostat $\left.^{\odot}\right)$ reduce the incidence of postoperative pancreatic fistula after distal pancreatectomy? A matched pairs analysis. Acta Chir Belg 2021; 121: 16-22.

19. R Core Team (2019). R: A language and environment for statistical computing. R Foundation for Statistical Computing, Vienna, Austria. URL https:// www.R-project.org/

20. Baron DM, Franchini M, Goobie SM, Javidroozi M, Klein AA, Lasocki S, Liumbruno GM, Muńoz M, Shander A, Spahn DR, Zacharowski K, Meybohm P. Patient blood management during the COVID-19 pandemic: a narrative review. Anaesthesia 2020; 75: 1105-13.

21. Kawamura M, Sawafuji M, Watanabe M, Horinouchi H, Kobayashi K. Frequency of transmission of human parvovirus B19 infection by fibrin sealant used during thoracic surgery. Ann Thorac Surg 2002; 73: 1098-100.

22. Scheule AM, Beierlein W, Wendel HP, Eckstein FS, Heinemann MK, Ziemer G. Fibrin sealant, aprotinin, and immune response in children undergoing operations for congenital heart disease. J Thorac Cardiovasc Surg 1998; 115: 883-9.

23. Graziano F, Certo F, Basile L, Maugeri R, Grasso G, Meccio F, Ganau M, Iacopino DG. Autologous fibrin sealant $\left(\operatorname{Vivostat}\left({ }^{\circledR}\right)\right)$ in the neurosurgical practice: Part I: Intracranial surgical procedure. Surg Neurol Int 2015; 6: 77. 